\title{
ADDING OXYGEN TO ARGO: DEVELOPING A GLOBAL IN-SITU OBSERVATORY FOR OCEAN DEOXYGENATION AND BIOGEOCHEMISTRY
}

\author{
Nicolas Gruber $^{(1)}$, Scott C. Doney ${ }^{(2)}$, Steven R. Emerson ${ }^{(3)}$, Denis Gilbert ${ }^{(4)}$, Taiyo Kobayashi ${ }^{(5)}$, \\ Arne Körtzinger ${ }^{(6)}$, Gregory C. Johnson ${ }^{(7)}$, Kenneth S. Johnson ${ }^{(8)}$, Stephen C. Riser ${ }^{(3)}$, and Osvaldo Ulloa ${ }^{(9)}$ \\ ${ }^{(1)}$ Institute of Biogeochemistry and Pollutant Dynamics, ETH Zurich, Universitaetstrasse 168092 Zürich, Switzerland. \\ Email: nicolas.gruber@env.ethz.ch \\ ${ }^{(2)}$ Woods Hole Oceanographic Institution, 266 Woods Hole Road, Woods Hole, MA 02543, USA. \\ Email: sdoney@whoi.edu \\ ${ }^{(3)}$ School of Oceanography, University of Washington, P.O. 355351, Seattle WA, 98195, U.S.A. \\ Email:emerson@u.washington.edu; riser@ocean.washington.edu \\ ${ }^{(4)}$ Department of Fisheries and Oceans, Institut Maurice-Lamontagne, 850 Route de la Mer, Mont-Joli, \\ Québec G5H 3Z4, Canada. Email: Denis.Gilbert@dfo-mpo.gc.ca \\ ${ }^{(5)}$ Institute of Observational Research for Global Change and Japan Agency for Marine-Earth Science and Technology, \\ 2-15 Natsushima, Yokosuka, Kanagawa, 237-0061, Japan; Email: taiyok@jamstec.go.jp \\ ${ }^{(6)}$ Leibniz-Institut für Meereswissenschaften at the University of Kiel, Düsternbrooker Weg 20, D-24105 Kiel, Germany; \\ Email: akoertzinger@ifm-geomar.de \\ ${ }^{(7)}$ NOAA (National Oceanic and Atmospheric Administration) Pacific Marine Environmental Laboratory, 7600 Sand \\ Point Way N.E., Seattle, WA 98115-6349, USA; Email: Gregory.C.Johnson@noaa.gov \\ ${ }^{(8)}$ Monterey Bay Aquarium Research Institute, 7700 Sandholdt Road, Moss Landing, CA 95039-USA \\ Monterey, CA, USA; Email: johnson@mbari.org \\ ${ }^{(9)}$ Departamento de Oceanografía \& Centro de Investigación Oceanográfica, Universidad de Concepción, Cabina 7 - \\ Barrio Universitario, Casilla 160-C, Concepción 3, Chile.Email: oulloa@udec.cl
}

\begin{abstract}
We propose to add dissolved oxygen sensors to the Argo (Global array of free-drifting profiling floats) float program in order to determine, on a global-scale, seasonal to decadal time-scale variations in dissolved oxygen concentrations throughout the upper ocean. Such observations are especially important to document the ocean's expected loss of oxygen as a result of ocean warming, but there are many other benefits including the opportunity to estimate net community and export production, the assessment of changes in low oxygen regions, and improved estimates of the oceanic uptake of anthropogenic $\mathrm{C}_{\mathrm{O} 2}$.
\end{abstract}

The proposed joint Argo-Oxygen program is made possible by the recent development of dissolved oxygen sensors that are both precise and stable over extended periods and can be easily integrated with the currently used Argo floats. Results from the more than 200 oxygen equipped Argo float have not only demonstrated the feasibility of the program, but also produced already many insights and discoveries. Achieving the main goal of the Argo-Oxygen program does not require any appreciable changes in the deployment and operating strategies of the current Argo program and can therefore be implemented without a significant impact on Argo's core mission.

A two-phase implementation is proposed, consisting of a small set of regional pilot-studies, followed by a buildup toward a global implementation. The cost of adding oxygen sensors to all floats of the Argo program is estimated to be about USD 4.2 million per year. The proposed Argo-Oxygen program will add substantial value to Argo by expanding the number of Argo data users, as well as by creating new synergies between the physical and the biogeochemical ocean research communities. The new observations will also contribute to the activities of various international networks and partnerships for Earth Observing Systems.

\section{INTRODUCTION}

The oceans have warmed considerably in the last few decades, and are projected to warm even more by the end of this century. The impacts of this heat uptake on ocean circulation, ocean biogeochemistry, and biology are not well established. One important reason for this limited understanding is the chronic spatial and temporal undersampling of the ocean. The highly successful Argo has fundamentally altered this situation for physical properties, since for the first time, the ocean's interior has become accessible to observations at adequate temporal and spatial scales (e.g. [1]).

This dramatic shift in observational capabilities has not yet been paralleled by similar advances in observations of the large-scale biogeochemical and biological state of the ocean. At present, the primary mode of observing the ocean's interior evolution of biogeochemically and biologically relevant properties is by sampling from research vessels. To date, the most ambitious international program to map out the distribution of biogeochemical tracers in the ocean was the global $\mathrm{CO}_{2}$ survey undertaken jointly by the World Oceanographic Circulation Experiment (WOCE), the Joint Global Ocean Flux Study (JGOFS), and a few other national 
programs [2]. This survey, which took a decade to complete, resulted in the order of 100,000 biogeochemically relevant measurements, increasing the total number of observations for many parameters up to tenfold. However, this survey was largely a one-time snapshot, providing limited information about temporal evolution. Subsequently, a new international program was launched - the Repeat Hydrography Program (see [3] - but despite very substantial international efforts, the average time between repeats of hydrographic sections is about a decade, with large parts of the ocean not being sampled at all.

This repeat cycle and sparse spatial sampling is adequate for determining the long-term increase of the oceanic carbon content in response to the increase of atmospheric $\mathrm{CO}_{2}$ [4], but a decade is substantially longer than the seasonal to sub-decadal time-scale that characterizes much of the thermocline variability in many biogeochemical parameters, as exemplified by the rapid changes in thermocline oxygen concentrations seen in the northeastern North Atlantic along $20^{\circ} \mathrm{W}$ (Fig. 1). In addition, the relatively coarse spatial separation between sections is likely to be barely adequate to resolve sub- basin-scale variations in gyres and their water properties.

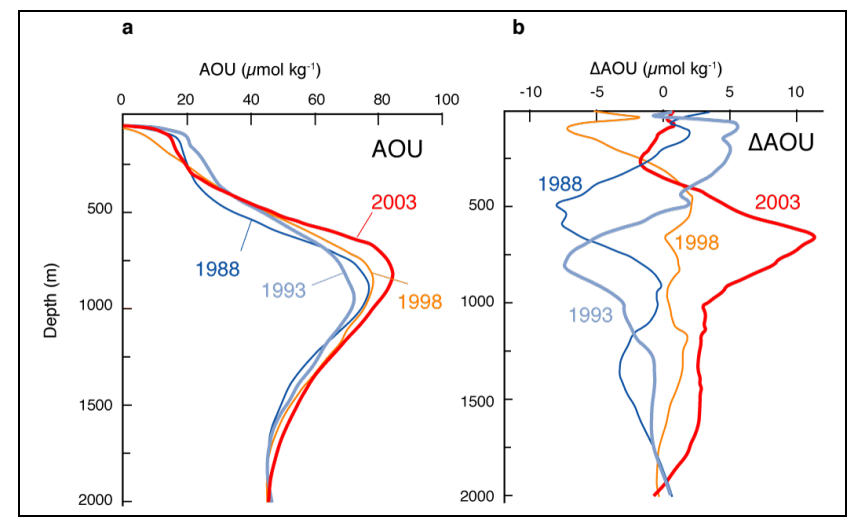

Figure 1: Time evolution of the Apparent Oxygen Utilization (AOU) in the North Atlantic from 1988 until 2003 , averaged from $40^{\circ} \mathrm{N}$ to $64^{\circ} \mathrm{N}$ along $20^{\circ} \mathrm{W}(\mathrm{AOU}=$ $\left.\left[\mathrm{O}_{2}\right]^{\text {sat }}-\left[\mathrm{O}_{2}\right]^{\text {measured }}\right)$. (a) Mean profiles of AOU for the four occupations of the $20^{\circ} \mathrm{W}$ line from 1988 through 2003. (b) Difference from the mean AOU profile of all 4 cruises. From [5].

These undersampling problems could be easily overcome if biogeochemical or biological sensors could be added to profiling floats. However, until very recently, such biogeochemical /biological sensors suitable for use on Argo-type floats were not available. The rapid recent development in sensor technology [6] makes the expansion and augmentation of the Argo network for biogeochemistry/biology now possible. By far the most advanced sensors in terms of development and long-term experience with deployment on Argo floats are those for dissolved oxygen $\left(\mathrm{O}_{2}\right)$ (Fig. 2) (see [7]) for a discussion of other biogeochemical/biological sensors). Polarographic oxygen sensors have been deployed on Argo floats since 2002. More recently, the optode, which takes advantage of dynamic luminescence of luminophores that fluoresce depending on $\mathrm{O}_{2}$, became available for float deployment ([8-10]). To this date (October 2009), more than 400 floats with oxygen have been deployed.

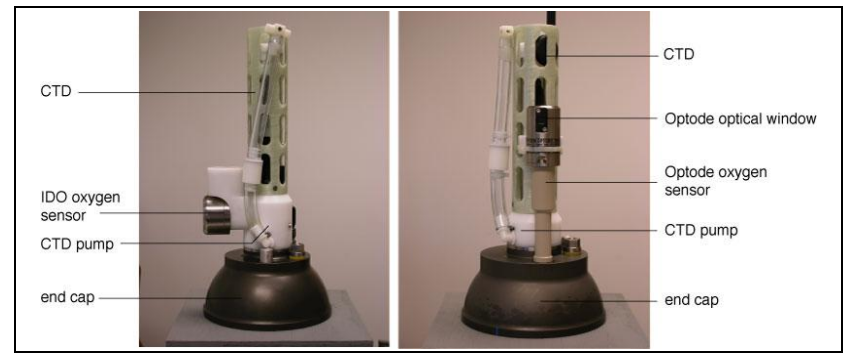

Figure 2: (Left photo) Upper portion of an APEX (Autonomous Profiling Explorer) float, showing the SeaBird CTD (Conductivity-Temperature-Depth) unit and dissolved $\mathrm{O}_{2}$ sensor. (Right photo) An Aanderaa Optode sensor mounted on an APEX float end cap. (Photos from S. Riser).

This white paper aims to develop and present the scientific justification as well as the practicality of adding $\mathrm{O}_{2}$ sensors to the Argo array in order to determine the seasonal to decadal time-scale variations of the ocean's oxygen content. The Argo-Oxygen program will constitute an order of magnitude or more increase in our ability to observe the biogeochemical state of the ocean, with repercussions and benefits for many other aspects of oceanography.

Why is a full-fledged observatory of oxygen in the ocean needed? The (mostly) decreasing trends in the concentrations of dissolved oxygen in the ocean over the last few decades (cf. [11-13]) have important implications for our understanding of anthropogenic climate change. The absolute amount of oxygen in a given location is very sensitive to changes in circulation and biology. It may be more sensitive, perhaps, than other physical and chemical parameters. Oceanic oxygen has therefore been proposed as a bellwether indicator of climate change, analogous to the canary in the coal mine [14]. But, as we will show below, an enhanced oxygen observatory in the ocean can do much more for us.

Oceanic measurements of dissolved oxygen have a long history, and oxygen is the third-most oft-measured water property (behind temperature and salinity). By joining forces under the Argo sail, oceanographers from various parts of the community could foster a renaissance of oxygen as a classical oceanographic 
parameter, helping us identify and understand global climate change.

\section{SCIENTIFIC OBJECTIVE}

The key scientific objective of the Argo-Oxygen program is

To determine seasonal to decadal-time variability in sub-surface ocean oxygen storage and transport on a global scale.

As the temporal and spatial scales of oxygen variability are similar to those of temperature, and the Argo array is designed to achieve these objectives for temperature, they can be achieved for oxygen by extending the presently operating global Argo program to include oxygen sensors on their floats, without requiring any changes in the operating cycle of the floats. However, achieving these objectives requires accurate and precise long-term measurements of the dissolved oxygen concentration as outlined in more detail below.

\section{SCIENTIFIC RATIONALE}

There are many scientific reasons for undertaking detailed global-scale measurements of the temporal evolution of the ocean's oxygen distribution. These include:

- Detect and documents the ocean's deoxygenation

- Prediction and assessment of anoxic or hypoxic events

- Determine seasonal to interannual changes in net community and export production

- Improve atmospheric $\mathrm{O}_{2} / \mathrm{N}_{2}$ constraint on the oceanic uptake of anthropogenic $\mathrm{CO}_{2}$

- Aid interpretation of variations in ocean circulation/mixing

- Provide constraints for ocean biogeochemistry models

- Aid in interpretation of sparse data from repeat hydrographic surveys

- Determine transport and regional air-sea fluxes of oxygen

We subsequently discuss only the first two rationales. Readers interested in the other justifications are referred to [15].

\subsection{Detect and document the ocean's deoxygenation}

Model simulations indicate that the ocean's oxygen content will respond very sensitively to global ocean warming, with the magnitude of the oxygen loss (deoxygenation) exceeding that expected on the basis of the solubility decrease by a factor of 3 to 4 [cf. 13]. This prediction is a result of biologically/physically induced changes in the oxygen outgassing flux, which tend to act in concert with those induced by heating/cooling [16].

The expected ocean deoxygenation may be quite substantial, i.e. up to a $17 \%$ reduction of the ocean's oxygen content by 2100 [16]. This reduction will be accompanied with a substantial increase in the extent of the oxygen minimum zones. Reference [17] suggested a doubling of the regions with suboxia $\left(\mathrm{O}_{2}<10 \mu \mathrm{mol} \mathrm{kg}\right.$ ${ }^{1}$ ), i.e. a doubling of the marine "dead-zones" with severe implications for all higher life-forms and for long-term nutrient inventories and cycles. Reference [18] showed that some of these low-oxygen regions have already experienced a substantial oxygen loss over the last 40 years (Fig. 3).

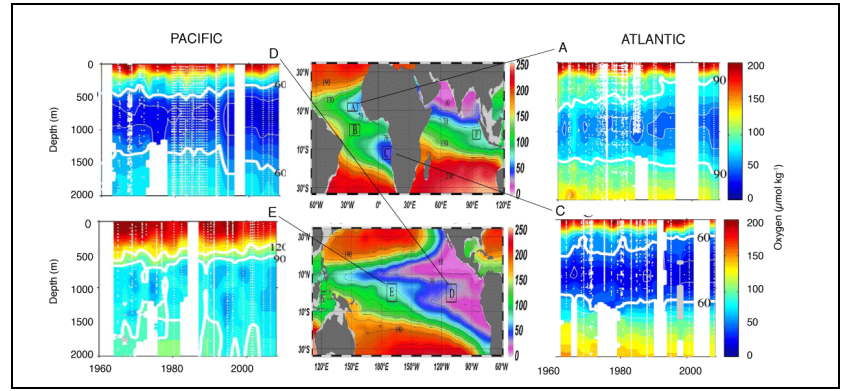

Figure 3: 40year timeseries of oxygen from four lowoxygen sites in the Tropical Atlantic and Tropical

Pacific. The core of the low-oxygen waters in areas A and $C$ in the Atlantic have significant negative long term oxygen trends, while they are not statistically significant in the Pacific. Taken together, they point toward a substantial loss of oxygen from the tropical low oxygen regions. Modified from [18].

Presently available observations of the long-term evolution of the ocean's oxygen content largely show decreases in the oxygen content (cf. [13] and references therein) consistent with the expected trend based on the ocean's warming. However, there are also regions where oxygen has increased recently such as the southern Indian Ocean [19], possibly reflecting natural variability in the oceanic system. The lengths of the records and the small number of regions with repeat sampling make it impossible to extrapolate these observations to larger regions or even to the globe in order to assess the global-scale oxygen balance of the ocean. The addition of oxygen sensors to the Argo array would in a few years alleviate the overwhelming undersampling problem for oxygen. However, the requirement to detect long-term changes in oceanic oxygen also places serious demands on the accuracy and long-term stability of the oxygen sensors (see below).

\subsection{Prediction and assessment of anoxic or hypoxic events}

Hypoxic or anoxic events in coastal waters represent a substantial threat to many coastal habitats, causing 
substantial environmental and economic damages (e.g. [20]). Although coastal eutrophication is an important driver for such events, the initial oxygen concentration of the deep-ocean waters advecting into the near-shore environments is an important determinant as well (e.g. [21]). For example, anomalous intrusions of Subarctic water into the California Current System led to the developments of severe inner-shelf hypoxia along the Oregon Coast and resultant mass mortality of fish and invertebrates in the summer 2002 [22] and 2006 [23]. Ref [24] present evidence of a long-term decline of oxygen in the St. Lawrence Estuary (Canada) from intrusions of oxygen-poor oceanic water. Therefore, detailed measurements of the oxygen concentrations in the open ocean source waters will permit much better prediction and assessment of such hypoxic or anoxic events. Such hypoxic events may become more frequent in the future, as global warming increased stratification of the open ocean will tend to decrease the oxygen concentration of the waters that usually advect toward the shore. This process may underlie already part of the trend toward more intense, longer, and more frequent coastal hypoxic events that has been observed in the last few decades [25].

\section{SHOWCASE EXAMPLE}

\subsection{Ocean Productivity constraints in the subtropical gyres}

Two floats, both equipped with Seabird SBE43 sensors for dissolved oxygen, were deployed in the subtropical Pacific to assess the balance of oxygen production and consumption, i.e. net community production [26]. One float (894) collected measurements for three years in the vicinity of the Hawaii Ocean Time series (HOT) station $\left(23^{\circ} \mathrm{N}, 158^{\circ} \mathrm{W}\right)$, whereas a second one $(1326)$ collected profiles for 3 years near $22^{\circ} \mathrm{S}, 120^{\circ} \mathrm{W}$ in the South Pacific. The two floats performed exceptionally well, providing unprecedented new information about the seasonal evolution of upper ocean oxygen (Fig. 4). Thanks to the proximity of the HOT time series station, the stability and performance of float 894 could be assessed in great detail. Analyses of the data from $1800 \mathrm{~m}$ demonstrates that the SBE sensor had a precision and stability over three years of better than 1.5 $\mu \mathrm{mol} \mathrm{kg}{ }^{-1}$. The accuracy was not as good, but within the manufacturer's specifications.

These data are well suited to examining the oxygen balance and net community production of subtropical waters because of the relatively rapid ten-day sampling time, high stability and precision of the oxygen measurements, and the fact that these floats remained in nearly homogeneous regions of the ocean for an extended period. From the rate of oxygen accumulation underneath the surface mixed layer, an annual mean net community production of about $1.6 \pm 0.2 \mathrm{~mol} \mathrm{C} \mathrm{m}^{-2} \mathrm{yr}^{-1}$ for the area near the HOT site, and $0.9 \pm 0.4 \mathrm{~mol} \mathrm{C} \mathrm{m}^{-2}$ $\mathrm{yr}^{-1}$ for the South Pacific area was estimated. The former compares well with a series of independent estimates (e.g., [27]), while the latter constitutes the first estimate of net community production in the South Pacific subtropical gyre.

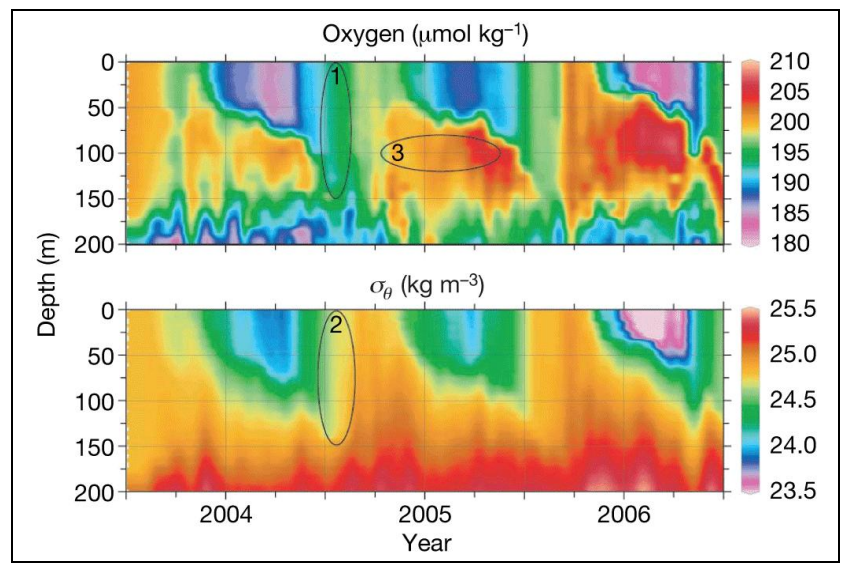

Figure 4: Contours of the evolution of (a) oxygen concentration and $(b)$ density in the upper $200 \mathrm{~m}$ from Argo float 1326 that sampled the western South Pacific in the vicinity of $23^{\circ} \mathrm{S}$ and $121^{\circ} \mathrm{W}$. A period of convective overturn in 2004, during which oxygen and density become vertically homogenous, are identified by ellipses labelled 1 and 2, respectively. The subsequent oxygen increase to form the seasonal oxygen maximum is identified by the ellipse labelled 3. Modified from [26].

\section{TECHNICAL ASPECTS: PRESENT STATUS AND DEVELOPMENT NEEDS}

\subsection{Sensors}

To date, two types of dissolved $\mathrm{O}_{2}$ sensors have been employed on profiling floats. The SBE-IDO (Sea-Bird Electronics-Integrated Dissolved Oxygen) (formerly known as the SBE-43) implementation, from SeaBird Electronics, is an electrochemical sensor (Clark cell) [28] whose design is similar to the $\mathrm{O}_{2}$ sensors on SeaBird shipboard CTD units. The Aanderaa Optode is an optical sensor that operates on the principle of fluorescence quenching [10]. The IDO sensor is fully integrated into the SeaBird float CTD system (Fig. 2, left; note that over $90 \%$ of Argo floats currently employ a SeaBird CTD system), while the optode is mounted onto the end cap.

The accuracy and precision requirements for the sensors to meet the scientific goal described above are quite stringent. For accuracy, we determined a threshold of about $5 \mu \mathrm{mol} \mathrm{kg}-1$ and a target of $1 \mu \mathrm{mol} \mathrm{kg}-1$ (threshold is the level above which the data are of insufficient quality to address scientific objectives, while the target is the desired level of data quality). For precision, we consider a threshold of $2 \mu \mathrm{mol} \mathrm{kg}{ }^{-1}$ as acceptable, while the target precision should be $0.5 \mu \mathrm{mol} \mathrm{\textrm {kg } ^ { - 1 }}$. These 
requirements are based on two main considerations: First, this level of precision and accuracy is required in order to properly observe the seasonal amplitude of oxygen in the upper thermocline, which amounts to about 10 to $20 \mu \mathrm{mol} \mathrm{kg}{ }^{-1}$ (e.g.[26 and 29]). Second, the expected long-term trend of oxygen in the upper ocean as a result of ocean deoxygenation amounts to about 5 to $20 \mu \mathrm{mol} \mathrm{kg}{ }^{-1}$ over a decade [13], putting stringent constraints on accuracy and long-term drift as well. We thus ask that the long-term drift should not exceed the threshold accuracy. However, we envision that some of the long-term drift problems can be corrected by combining the oxygen measurements from the floats with independent measurements, taken, for example, from repeat hydrography cruises. There exist also the possibility to use air measurements to assess drift (see below).

Another issue of importance is the response (equilibration) time of the sensor plus the time it takes for the actual measurement. This total measurement time is a crucial factor, since measurements need to be taken during transit through a vertical oxygen gradient. With a typical ascent speed of $0.1 \mathrm{~m} \mathrm{~s}^{-1}$, and vertical

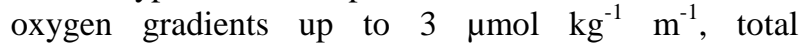
measurement times (i.e. e-folding times) of considerably more than 10 seconds will result in a smearing-out effect that can lead to errors of a magnitude comparable to the target accuracy of $1 \mu \mathrm{mol} \mathrm{kg}{ }^{-1}$ [9]. Therefore, total measurement times of less than 10 seconds are preferred, while 30 seconds is about the threshold. For deployments in systems that are characterized by extremely strong vertical gradients in dissolved oxygen (up to $18 \mu \mathrm{mol} \mathrm{kg} \mathrm{k}^{-1} \mathrm{~m}^{-1}$ ), the required response time would have to be shorter.

Reference [17] summarized the studies that have been undertaken so far with regard to the precision, accuracy, stability, and response time of the two sensors. Their conclusion, which is still more or less valid at this point in time (September 2009), is that both sensors have their strengths and weaknesses with regard to these criteria.

The advantages of the Optode sensor appear to be its excellent long-term stability and high precision. It also appears to be accurate provided that it has sufficient time to come into equilibrium with the surrounding temperature and oxygen concentration and provided that its temperature response has been carefully calibrated (possibly by individual sensor factory-calibration plus in-situ calibration check/correction based on concomitant Winkler profile). In addition, the Optode sensor provides for the opportunity to use atmospheric $\mathrm{O}_{2}$ as a calibration [9]. The main disadvantage of the current generation Optode sensor is its relatively slow response time, which tends to lead to problems in the upper ocean, where vertical gradients in dissolved oxygen and temperature are greatest. A new Optode sensor is now on the market $(4330 \mathrm{~F})$ with a much faster response time, but no long-term deployments with floats have been undertaken so far, preventing us from assessing its performance. The advantage of the IDO is its high precision and its faster response time. It tends to be somewhat less accurate than the Optode sensor and also tends to have higher drift.

Relative to the threshold and target specifications of the program, both sensors do well with regard to precision, but improvements are needed in terms of accuracy and long-term stability for both sensors. For the Optode, improvements in its response time behavior are also needed, even for the newer sensor with faster response time.

This assessment is based on the current generation of sensors. However, both companies are currently in the process of improving their sensors. Nevertheless, the high levels of accuracy and precision needed to address some of the scientific questions outlined above will likely require additional careful testing and calibration of the sensors before deployment of these sensors in large numbers is undertaken, and significant postprocessing of the data will likely be required.

\subsection{Sensor integration \& communications \& energy requirements}

Most oxygen sensors deployed to date (about equal numbers of Optodes (optical sensors) and IDO) have been installed on APEX floats. The Anderaa Optode has been installed also on Provor floats, and several successful deployments have been undertaken. In the latter float type, the sensor was installed in the bottom for space reasons. However, the system is currently being redesigned to accommodate also a mounting at the top in order to benefit from the potential to use atmospheric $\mathrm{O}_{2}$ to assess the long-term stability.

The exact operation of the oxygen-equipped float depends primarily on the communication protocol being used as this determines how much data can be transmitted at the surface. For the future, it is anticipated that Iridium or a similarly fast system is the primary communication protocol employed. In such a case, 1000 measurements are being taken, resulting in a very fine vertical resolution. For more details, the reader is referred to [15]).

The actual increase in energy required to operate a dissolved $\mathrm{O}_{2}$ sensor in four APEX cases (ARGOS-IDO, ARGOS-Optode, Iridium-IDO, and Iridium-Optode) has been measured recently at the UW Float Lab using floats that were under pressure. Using this information, the maximum number of profiles and the maximum float lifetime has been estimated, assuming that profiles are collected at 10-day intervals and assuming that floats will fail due to dead batteries. In addition, it is assumed that the floats are equipped with 3 lithium battery packs. These analyses reveal that the addition of 
dissolved oxygen sensors will reduce the float lifetime by between $10 \%$ to $30 \%$, depending on the exact configuration.

\subsection{Current costs estimates}

The costs of the proposed Argo-Oxygen program arise from the sum of several components. The following elements need to be considered: (i) costs of the oxygen sensors, (ii) costs for adding the sensors to the floats, (iii) costs for testing or calibrating the sensors, (iv) costs affecting the float lifetime from any increased energy demand from sensor operation, float operation, or increased data transmission requirements, (v) telecommunications costs, (vi) costs for data handling, and (vii) costs for data quality control. These additional expenses have to be compared to the costs associated with a standard Argo float that measures temperature and salinity only.

The total estimated 5-year cost per float of the ArgoOxygen program above the core Argo mission comes to about US\$6500 to US\$9200, or about US\$1300 to US $\$ 1840$ per float and year (see Table 1). These estimates are based on actual measurements plus the experience from tens of float deployments undertaken by the UW float group (see [15] for details). With a profile every 10 days, the per profile cost amounts to between US\$36 and US\$50. If we disregard the APEX/ARGOS/IDO option, which is particularly expensive due to its substantial reduction in float lifetime, this represents an increase of roughly $40 \%$ relative to the cost of operating the core mission of Argo.

Table 1:

\begin{tabular}{llllllll}
\hline $\begin{array}{l}\text { Configuration } \\
\text { (APEX float) }\end{array}$ & $\begin{array}{l}\mathrm{O}_{2} \\
\text { Sensor }\end{array}$ & $\begin{array}{l}\text { Sensor } \\
\text { Preparation }\end{array}$ & $\begin{array}{l}\text { 5-Year } \\
\text { Communic } \\
\text { ation Cost }\end{array}$ & $\begin{array}{l}\text { Incremental } \\
\text { Cost From } \\
\text { Reduced } \\
\text { Float } \\
\text { Lifetime }\end{array}$ & $\begin{array}{l}\text { Data } \\
\text { Handling } \\
\text { C Control }^{\mathrm{b}}\end{array}$ & $\begin{array}{l}\text { Total } \\
\text { Estimated } \\
\text { Cost } \\
\text { Float }\end{array}$ & $\begin{array}{l}\text { Change } \\
\text { Pert }\end{array}$ \\
$\begin{array}{l}\text { Relative } \\
\text { To T/S }\end{array}$ \\
ARGOS/Optode & 3800 & 400 & 500 & 1800 & 1000 & 7500 & $+47 \%$ \\
ARGOS/IDO & 2800 & 100 & 500 & 4800 & 1000 & 9200 & $+58 \%$ \\
Iridium/Optode & 3800 & 400 & 70 & 1800 & 1000 & 7070 & $+40 \%$ \\
Iridium/IDO & 2800 & 100 & 470 & 2200 & 1000 & 6570 & $+37 \%$ \\
\hline
\end{tabular}

Table 1: Estimates of the total 5-year cost of adding oxygen measurements to Argo on a per float basis. Shown are the marginal costs only, i.e. those above the operation of the core Argo program. All costs in the table are given in US\$ and all prices are based on typical costs in the US.

\section{NOTES:}

a: Estimated from the relative reduction of the float life-time given in Table 3 and the total purchase cost of an APEX T/S float given in Table 4, i.e. US\$14,000 for an APEX/ARGOS float and US\$16,000 for an APEX/Iridium float.

b: Estimate based on experience with quality control for salinity.

c: Relative to the total 5 year operation cost of an APEX T/S float, i.e. US\$15,800 for an APEX/ARGOS float and US\$17,530 for an APEX/Iridium float.

\subsection{Summary and Recommended Action Items for the near-term}

In conclusion, the technology for an Argo-Oxygen program is nearly ready, but several problems with the sensors and their integration with CTD units need to be solved before a global-scale deployment is justifiable.
The good news is that the problems noted here, while not unimportant, are solvable in the near-term. In order to accelerate progress, we recommend that the following action items be implemented as soon as possible:

(1) Continue Sensor development: Drift problems with the IDO and long response times for the Optode limit the usefulness of these two very promising sensors. Continuing development and testing of these two sensors should be encouraged in order to improve their performance.

(2) Improve Calibration: The manufacturers should be encouraged to redouble their efforts at understanding the calibration problems and provide remedies as soon as possible.

(3) Continue analyses of presently collected float data: With over more than 200 floats with dissolved oxygen sensors already in the ocean, more detailed analyses of the sensor performance are possible, across a wider range of oceanographic conditions. 
Many of these action items are already being addressed at the time of writing, so that we can expect much progress in the coming months.

\section{IMPLEMENTATION}

\subsection{Overview}

In the last few years, more than 200 floats bearing oxygen sensors have been deployed so far. Most of them are still active, with 160 floats having reported data during 20 days in May 2009 (Fig. 5). The distribution of these floats is not the result of a coordinated effort, but reflects the scientific interests of the pioneering PIs who deployed them. As a result, the currently deployed oxygen equipped floats do not form a larger-scale observing network, although they could provide the seeds for it. Therefore, one option for the implementation of the Argo-Oxygen program envisioned here is to directly build on these pioneering efforts and simply increase the number of deployments until a satisfactory global network is achieved. However, the current status of the sensor development as well as open issues with regard to communication, data handling, and data quality control suggest that it may be prudent to implement the Argo-Oxygen program in two distinct stages, i.e. a pilot phase, wherein the effort is focused on a few regions only, followed by the global implementation phase. Detailed planning for both phases is well beyond the scope of this CWP, so we limit our discussion to the delineation of a road map.

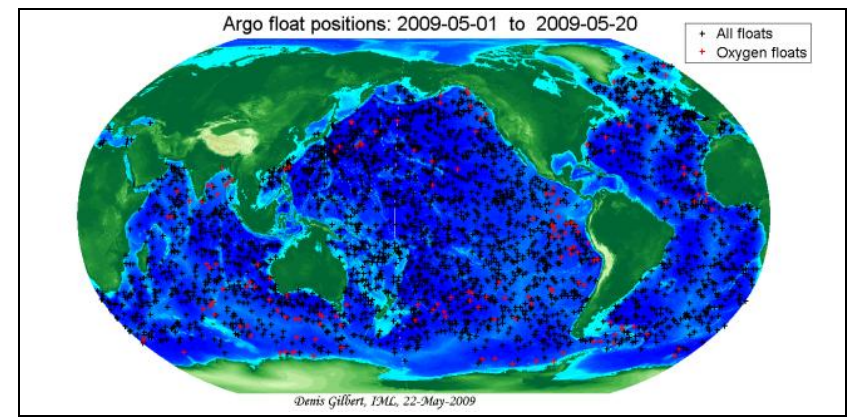

Figure 5. Map showing the locations of the 160 floats that reported oxygen data to the US GDAC (Global Data Assembly Center) between May 01 and May 20, 2009.

\subsection{Pilot phase}

The main goals of the pilot phase are (i) to prove the feasibility and value of the proposed Argo-Oxygen Program, and (ii) to provide for a well-sampled testing ground that permits an examination and solution of outstanding issues associated with sensor quality, data transmission, data handling and data quality control. It will also serve as a pilot project for the development of new data analyses and interpretation approaches, including data assimilation. Experience from the pilot phase will be directly fed into the planning for the global implementation.

For the pilot phase, a few regions should be selected and then instrument with a large number of floats with oxygen sensors in order to ensure that the spatial and temporal variability of oxygen in this region is well resolved, perhaps even over-sampled. It is envisioned that many floats will carry multiple oxygen sensors in order to assess the relative performance of the sensors. The main criterion for determining the selection of the region is that the temporal and spatial dynamical nature of its oxygen distribution is scientifically compelling to warrant such an effort. It will also be advantageous to select a region where regular ship surveys permit the possibility of obtaining bottle samples that can be analyzed by Winkler titration, providing for an absolute reference point. An additional criterion for region selection might include the existence of prior observations, permitting the backward extension of the newly gathered records. Finally, the existence of large range in oxygen concentrations within the water column might be beneficial, as this would allow more thorough tests of the sensor response and stability. Possible candidate regions are the high-latitude North Atlantic (Labrador and Irmiger Seas), the subarctic Pacific, the oxygen minimum zones of the tropics, and the regions around the subtropical timeseries stations HOT (Hawaii), BATS (Bermuda), and ESTOC (Canary Islands).

We envision that the pilot phase would last for about two years, in order to ensure thorough testing of the sensors and the observing array, and in order to guarantee the scientific benefit. Planning and initial steps for the global implementation will not have to wait for the end of the pilot phase. In fact, many relevant insights will likely already be available after the first year.

In order to avoid interference with the core Argo mission, the pilot phase of the Argo-Oxygen program will have to be conducted as an independent project with an independent float deployment plan. We envision that of the order of several tens of floats with $\mathrm{O}_{2}$ sensors will be deployed in a relatively tight spatial grid, together with an initial survey of the region's oxygen distribution based on shipboard Winkler titrations. In order to obtain higher frequency data, a fraction of the floats may be programmed to operate on a faster cycle than the typical 10 day repeat cycle of Argo. This pilot phase may also be used to test other platforms and sensors, such as gliders and a range of other biogeochemical or optical sensors (see e.g.[7]).

The Argo-oxygen program will have to bear the full cost of the floats and the sensors. As a ballpark estimate, the purchase of 100 floats with two oxygen sensors and 
their operation over 2 years will cost on the order of US\$ $2.5 \mathrm{M}$ (see Tab. 1). Shiptime, salaries, and the cost for making the shipboard Winkler oxygen titration measurements will have to be added to this sum. Although the total cost will depend greatly on the details of the program (number of floats), the selected region, and the level of ancillary activities, it appears as if a substantial pilot project can be undertaken with a level of funding somewhere between US\$ 5M to 10M.

The support of ancillary studies will be of great importance for the success of the pilot project and the demonstration of the feasibility and usefulness of the Argo-Oxygen program. These activities will have to include (i) sensor quality assessment studies, (ii) data assemblage and automatic quality control studies, (iii) data interpretation and interpolation studies, (iv) network design and optimization studies, and (iv) studies that attempt to incorporate the observations into modeling frameworks (using diagnostic or inverse methods) in order to take advantage of process information. In addition, the pilot studies would benefit from the incorporation of atmospheric oxygen measurements in order to independently assess the integrated changes in oceanic oxygen over the study region.

While no large-scale concerted Argo-Oxygen project has been funded so far, the rapid increase of oxygen equipped floats have de facto already created a number of smaller-scale pilot studies. While none of them have reached the desired density to fully assess oxygen variability, a few regions are close (Fig. 5). In addition, a project got recently funded to deploy several oxygen sensor equipped floats around the time-series sites HOT, BATS, and Station "P".

Data from these sensors are transmitted together with the regular Argo T/S data, and stored in the Argo data systems. However, no standardized quality control is in place yet. However, primary and secondary quality control procedures are currently developed by the community and one can anticipate that they will be implemented at the data centers once they have been thoroughly tested. In addition, several modeling groups have begun to explore the possibility of incorporating oxygen data into their assimilation models (see e.g. [30]).

\subsection{Global Implementation}

With the objective being a global one, only a global implementation of the Argo-Oxygen program will be able to achieve this goal. However, it is presently not yet known what sampling density will be required. As a first assumption, it is likely that the de-correlation length scale of oxygen variability is similar to that of temperature, so that eventually all 3000 floats will have to be equipped with an oxygen sensor.
Once the pilot studies have remedied some of the outstanding issues with regard to oxygen sensors, such an array can be built up over the time it takes to completely restock the present Argo array, which is about 5 years.

For the cost estimate, we assume that Argo is maintained, so that the Argo-Oxygen program would have to bear only the additional costs over and beyond the core of Argo. Assuming that the Argo-Oxygen goes for a full density coverage, about 600 floats need to be instrumented, deployed, and maintained per year. Assuming an extra cost of US\$ 7000 per float over 5 years, i.e. US\$ 1400 per float and year (see Tab. 1), this gives an annual expense of about US\$ 4.2 M per year. This estimate includes everything from sensor purchase, deployment, to extra data handling at the data centers. A more conservative estimate of a 4-year life-time of the floats requires a restocking rate of 800 per year, giving an annual cost of US\$ 5.6 M pear year.

A particularly attractive option is to combine this global array with extended measurements of atmospheric oxygen, as this permits to assess, in an independent manner, the net loss of oxygen from the ocean and hence to act as a check on the performance of the array. In addition, together, the two observing systems would permit a highly accurate determination of the fate of fossil fuel $\mathrm{CO}_{2}$.

\section{CONCLUSION}

The loss of oxygen in a warming world will pose a substantial challenge to a range of marine organisms, likely restricting the habitats of many fish and other higher organisms. This global-scale ocean deoxygenation will not occur in isolation, but concurs with ocean warming and ocean acidification, which could lead to amplification effects. The long-term loss will not occur in a smooth fashion, but will be characterized and overprinted by much smaller-scale temporal and spatial variations, so that the characterization of the long-term trend will be challenging unless a well resolved observing system is in place. The proposed Argo-Oxygen program will be well positioned to resolve such changes and to achieve its goal, i.e. "to determine seasonal to decadal-time variability in sub-surface ocean oxygen storage and transport on a global scale". The proposed program will be able to deliver much more, e.g. it can provide the data in order to determine seasonal net community and export production on a global scale, i.e. a critical element of the global carbon cycle, and it can provide critical observations to predict and assess coastal hypoxia.

The proposed Argo-Oxygen program builds on Argo, but can also make Argo more attractive by substantially enlarging its user base, and by providing links between 
the physical and biogeochemical user communities. The new observations will also contribute to the activities of various international networks and partnerships for Earth Observing Systems, such as the Climate Observing System/Global Ocean Observing System GCOS/ GOOS. It thus has large potential to create strong win-win situations.

\section{REFERENCES}

1. Gould, J., and the Argo Science Team, (2004). Argo Profiling Floats Bring New Era of In Situ Ocean Observations. EoS, Transactions of the American Geophysical Union, 85(19).

2. Wallace, D.W.R. (2001), Storage and transport of excess $\mathrm{CO}_{2}$ in the oceans: the JGOFS/WOCE Global $\mathrm{CO}_{2}$ Survey, in Ocean Circulation and Climate, G. Siedler, J. Church, W. J. Gould, Eds. (Academic Press, San Diego, CA, 2001), pp. 489-521.

3. Hood, M. \& Co-Authors (2010). "Ship-Based Repeat Hydrography: A Strategy for a Sustained Global Program." in these proceedings (Vol. 2), doi:10.5270/OceanObs09.cwp.44.

4. Bender, M., S. Doney, R.A. Feely, I.Y. Fung, N. Gruber, D.E. Harrison, R. Keeling, J.K. Moore, J. L. Sarmiento, E. Sarachik, B. Stephens, T. Takahashi, P.P. Tans, and R. Wanninkhof, (2002), A Large-Scale Carbon Observing Plan: In Situ Oceans and Atmosphere (LSCOP), pp. 201, Nat. Tech. Info. Services, Springfield.

5. Johnson, G. C. and N. Gruber (2007). Decadal water mass variations along $20^{\circ} \mathrm{W}$ in the northeastern Atlantic Ocean. Prog. Oceanogr., 73, doi:10.1016/j.pocean.2006.03.022, 277-295.

6. Johnson, K., J. Needoba, S. Riser, and W. Showers (2007) Chemical sensor networks for the aquatic environment. Chemical Reviews, 107, 623-640.

7. Claustre, H. \& Co-Authors (2010). "Bio-Optical Profiling Floats as New Observational Tools for Biogeochemical and Ecosystem Studies: Potential Synergies with Ocean Color Remote Sensing." in these proceedings (Vol. 2), doi:10.5270/OceanObs09.cwp.17.

8. Körtzinger, A., J. Schimanski, U. Send, and D.W.R. Wallace (2004). The ocean takes a deep breath. Science 306: 1337.

9. Körtzinger, A., J. Schimanski, and U. Send (2005). Highquality oxygen measurements from profiling floats: A promising new technique, J. Atm. Ocean. Techn. 22, 302308.

10. Tengberg, A.; Hovdenes, J.; Andersson, H. J.; Brocandel, O.; Diaz, R.; Hebert, D.; Arnerich, T.; Huber, C.; Kortzinger, A.; Khripounoff, A.; Rey, F.; Ronning, C.; Schimanski, J.; Sommer, S.; Stangelmayer (2006) A. Evaluation of a lifetime-based optode to measure oxygen in aquatic systems, Limnol. Oceanogr. Methods, 4, 7-17.

11. Joos, F., G.-K. Plattner, T.F. Stocker, A. Körtzinger, and D.W.R. Wallace (2003). Trends in marine dissolved oxygen: Implications for ocean circulation changes and the carbon budget. EOS Trans. AGU 84: 197-204.

12. Emerson, S., Y.W. Watanabe, T. Ono, and S. Mecking (2004). Temporal trends in apparent oxygen utilization in the upper pycnocline of the North Pacific: 1980-2000. J. Oceanogr. 60: 139-147.

13. Keeling, R. F., A. Kortzinger, and N. Gruber. Ocean Deoxygenation in a Warming World. Annual Review of Marine Science, Vol. 2: 199-229, 2010 doi:10.1146/annurev.marine.010908.163855...

14. Körtzinger, A., S. C. Riser, and N. Gruber (2006) Oceanic oxygen: the oceanographer's canary bird of climate change. ARGO Newsletter, 7, June 2006, 2-3.

15. Gruber N, S. C. Doney, S.R. Emerson, D. Gilbert, T. Kobayashi et al. 2007. The ARGO-oxygen program: A white paper to promote the addition of oxygen sensors to the international Argo float program. Available from www.ioccp.org/Docs/o2 argo whitepaper $15 \mathrm{feb} 07$ r.pdf pp. 1-60.

16. Gruber, N., E. Gloor, S.-M. Fan, and J. L. Sarmiento (2001), Air-sea fluxes of oxygen estimated from bulk data: Implications for the marine and atmospheric oxygen cycles, Global Biogeochem. Cycles, 15, 783-804.

17. Matear, R. J., and A. C. Hirst, (2003), Long-term changes in dissolved oxygen concentrations in the ocean caused by protracted global warming, Global Biogeochem. Cycles, 17(4), 1125, doi:10.1029/2002GB001997.

18. Stramma L, Johnson GC, Sprintall J, Mohrholz V. (2008) Expanding oxygen-minimum zones in the tropical oceans. Science, 320, 655-58

19. McDonagh, E. L., H. L. Bryden, B. A. King, R. J. Sanders, S.A. Cunningham and R. Marsh. 2005. Decadal changes in the South Indian Ocean thermocline, Journal of Climate, 18, 1575-1590.

20. Service, R. (2004) New dead zone off Oregon Coast hints at sea change in currents. Science, 305, 1099.

21. Kasai, A., T. Yamada, and H. Takeda (2007) Flow structure and hypoxia in Hiuchi-nada, Seto Inland Sea, Japan, Estuarine Coastal and Shelf Science, 71 (1-2): 210-217.

22. Grantham, B.A., F. Chan, K.J. Nielsen, D.S. Fox, J.A. Barth, A. Huyer, J. Lubchenco and B.A. Menge (2004) Upwelling-driven nearshore hypoxia signals ecosystem and oceanographic changes in the northeast Pacific. Nature, 429: 749-754.

23. Chan F, Barth JA, Lubchenco J, Kirincich A, Weeks H, et al. 2008. Emergence of anoxia in the California current large marine ecosystem. Science 319: 920-20.

24. Gilbert, D., B. Sundby, C. Gobeil, A. Mucci and G.-H. Tremblay (2005) A seventy-two year record of diminishing deep-water oxygen in the St. Lawrence estuary: The northwest Atlantic connection, Limnol. Oceanogr., 50 (5): 1654-1666 
25. Rabalais, N.N. and R.E. Turner (2001) Commonality and the future. In Coastal Hypoxia Consequences for living resources and Ecosystems, Eds: N.N Rabalais and R.E. Turner, American Geophysical Union, Coastal and Estuarine Studies, 58: 451-454.

26. Riser, S.C. and K. S. Johnson (2008) Net production of oxygen in the subtropical ocean, Nature 451, 323-325, doi:10.1038/nature06441.

27. Keeling, C. D., H. Brix, and N. Gruber (2004), Seasonal and long-term dynamics of the upper ocean carbon cycle at Station ALOHA near Hawaii, Global Biogeochem. Cycles, 18, GB4006, doi:10.1029/2004GB002227.

28. Clark LC, Wolf R, Granger D, Taylor Z (1953).

Continuous recording of blood oxygen tensions by polarography. J Appl Physiol. 6, 189-193.

29. Najjar, R G. and R. F. Keeling (1997) Analysis of the mean annual cycle of the dissolved oxygen anomaly in the World Ocean. J. Mar. Res. 55, 117-151.

30. Brasseur, P., N. Gruber, R. Barciela, K. Brander, M. Doron, A. El Moussaoui, A. J. Hobday, M. Huret, A.-S. Kremeur, P. Lehodey, C. Moulin, R. Murtugudde, I. Senina, E. Svendsen, R. Matear (2009) Integrating biogeochemistry and ecology into ocean data assimilation systems, Oceanography, 22(3), 192-201. 